\title{
Primary tuberculous lymphadenitis: A case report
}

This article was published in the following Dove Press journal:

Clinical, Cosmetic and Investigational Dentistry

6 May 2010

Number of times this article has been viewed

\author{
Velpula Nagalakshmi \\ Doggalli Nagabhushana \\ Anjum Aara \\ Department of Oral Medicine and \\ Radiology, Sri Sai College of Dental \\ Surgery, Kothrepally, Vikarabad, \\ Andhra Pradesh, India
}

\begin{abstract}
Tuberculosis (TB) is a prevalent systemic bacterial infectious disease usually caused by Mycobacterium tuberculosis. It is estimated that approximately 8 million people develop TB each year, and 3 million people die of complications associated with the disease. In this article we report a case of a 17-year-old female patient with a painful swelling in her right submandibular region. She was diagnosed with right submandibular tuberculous lymphadenitis. Tuberculous lymphadenitis, when occurring in the cervical region, continues to be a common cause of extrapulmonary TB. TB is a recognized occupational risk for dentists, as they work in close proximity to the nasal and oral cavities of patients, with the possible generation of potentially infectious sprays during routine operative procedures.
\end{abstract}

Keywords: submandibular, primary tuberculous lymphadenitis, tuberculosis

Tuberculosis (TB) is a systemic disease usually caused by Mycobacterium tuberculosis (MTB); however, M. avium, M. bovis, M. kansasii, and M. scrofulaceum have also been implicated as causes. ${ }^{1}$

Initial lesions are usually pulmonary, although an increase in extrapulmonary TB has been reported in recent years. These frequently involve the head and neck, with the most common presentation being a mass in the cervical region. ${ }^{2}$ Additionally, primary $\mathrm{TB}$ of the orofacial region is more commonly found in children and adolescents than in adults. ${ }^{3,4}$

Extrapulmonary TB is rare, accounting for about $10 \%-15 \%$ of all cases, thus posing a diagnostic challenge. ${ }^{5}$ Extrapulmonary TB may present in concurrence with a focus in the lungs or may present primarily without pulmonary involvement. The latter situation may provide a difficulty in diagnosis due to the absence of systemic signs and symptoms of the disease. ${ }^{6}$ Chest radiographs are required to rule out pulmonary $\mathrm{TB}$, even in those without systemic signs and symptoms of the disease.

TB is a worldwide health concern. Every year about 8 million people develop TB, and 3 million of these die of complications associated with the disease. ${ }^{8}$ It is estimated that $30 \%-60 \%$ of adults in developing countries are infected, with TB being the first cause of death among people aged over 5 years. ${ }^{9}$ According to the World Health Organization, TB is responsible for the deaths of approximately 2 million people each year and it is estimated that between 2002 and 2020, approximately 1 billion people will be newly infected, over 150 million people will get sick, and 36 million will die because of TB. ${ }^{10}$ The regions with the highest incidence rates are the Indian subcontinent, southeast Asia, and Africa. ${ }^{11}$ 
TB is a recognized occupational risk for dentists, as they work in close proximity to the nasal and oral cavities of patients, with generation of potentially infectious sprays during routine operative procedures a possibility. ${ }^{11}$ Nontreated active cases pose maximum risk to dental personnel. ${ }^{12}$ Only emergency dental cases should be undertaken for treatment in controlled environments for those with active TB. ${ }^{11,12} \mathrm{~A}$ major concern for dentists, in light of the reemergence of the disease, is the risk for transmission of TB in the dental setting. ${ }^{12}$ Furthermore, multi drug resistant TB, which is characterized by resistance to at least two of the four front line drugs (typically isoniazid and rifampicin), represents a challenge to TB control programs because its treatment is complex and frequently less successful than the treatment of nonresistant strains. ${ }^{13}$

Dentists are involved in the effort to control TB through identification and referral of patients who may require chemoprophylaxis or treatment and by developing and implementing an appropriate infection control program. The identification and treatment of oral lesions is also of importance to dental care providers. ${ }^{12}$ The constant risk of contracting the disease should encourage dental clinicians to follow basic precautions of using face masks, protective eye gear, and gloves. Also, high standards of operatory disinfection and instrument sterilization should be maintained. ${ }^{14}$

Identification of TB is of significance not only for the patient, but also for the dental team that comes in contact and the community at large where the patient can be a potential source for the spread of infection. ${ }^{15}$ Here we are presenting a case of oro-facial TB with right submandibular lymphadenitis.

\section{Case report}

A 17-year-old female patient reported to the Department of Oral Medicine and Radiology at Sri Sai College of Dental Surgery in Vikarabad, complaining of a painful swelling in her right submandibular region that had been present for two months and was originally noticed on June 13th 2009. The swelling was initially the size of a peanut and had been gradually increasing until it reached the present size. (Figure 1)

On general examination the patient was thin and malnourished. There were no fever, cough, or weight loss symptoms present. Past medical history and family history was not significant.

On extraoral examination, inspection showed a single diffuse swelling with ill-defined borders of approximately $4 \times 3 \mathrm{~cm}$ in the right submandibular region. The overlying skin was the same as surrounding skin. On palpation a mass was felt in the right submandibular region, which was

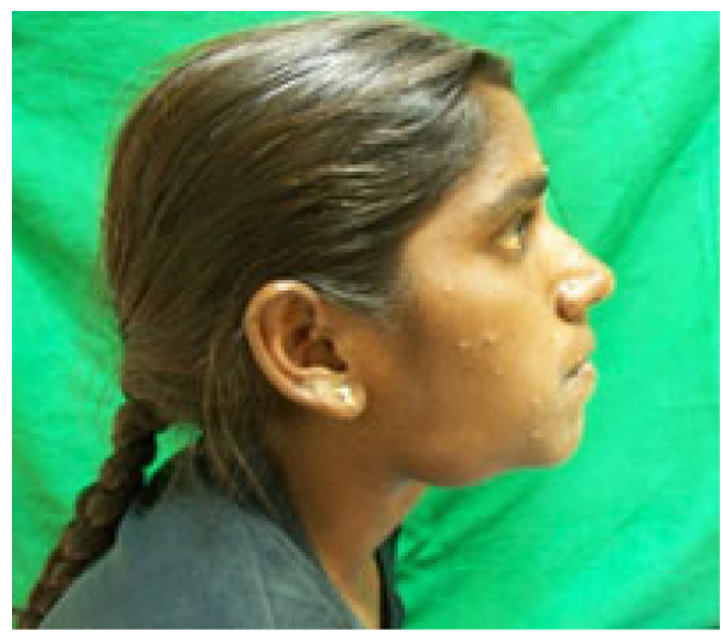

Figure I Swelling in right submandibular region.

firm in consistency, tender, nonfluctuant, noncompressible, mobile, and showed signs of matting (Figure 2). On intraoral examination, odontogenic involvement due to the swelling was not present. Other lymph nodes were not palpable.

A clinical diagnosis of right submandibular tuberculous lymphadenitis was considered. Differential diagnosis of right submandibular sialadenitis, right submandibular gland calcification was considered.

A panoramic radiograph was carried out and it did not reveal odontogenic origin in relation to the swelling (Figure 3). A Mantoux test was positive. No abnormality was detected in chest radiographs (Figure 4). A complete hemogram showed hemoglobin levels to be $8.8 \mathrm{gm} \%$, The red blood cell reading was $3.3 \mathrm{million} / \mathrm{cu} \mathrm{mm}$, and the total white blood cell count was 8,200 cells/cu mm. By comparison, normal range hemoglobin is $12 \%-16 \mathrm{gm} \%$, red

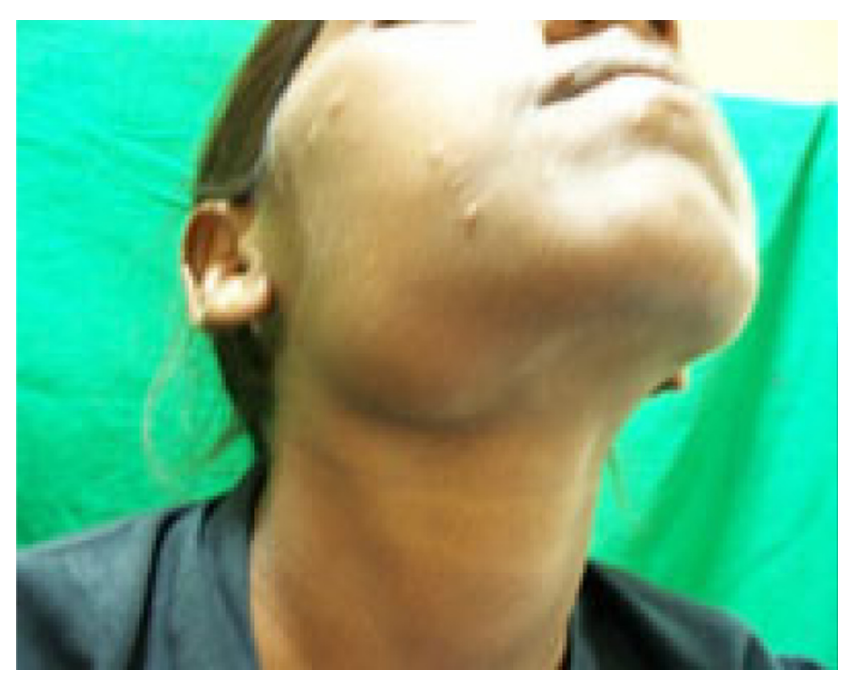

Figure 2 Swelling with ill-defined borders. 


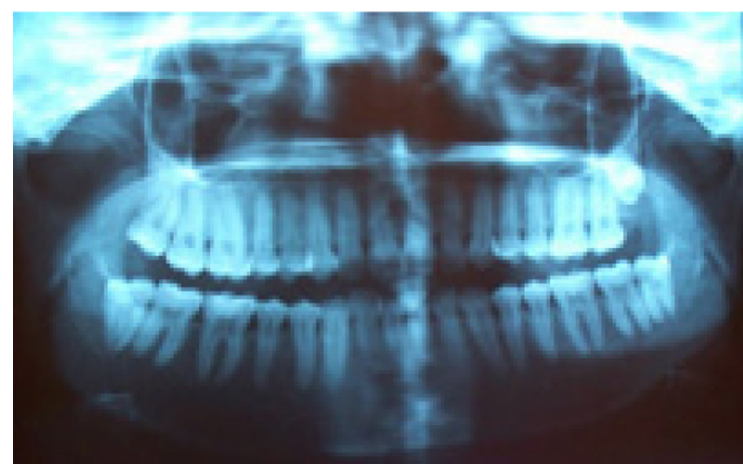

Figure 3 Panoramic radiograph showing no odontogenic orgin in relation to the swelling.

blood cells 4-5 million/cu mm, and total white blood cells 4000-11000 cells/cu mm. Erythrocyte sedimentation rate (ESR) was raised 1st hour $75 \mathrm{~mm}, 2$ nd hour $105 \mathrm{~mm}$.

A ultrasound scan of the patient's neck revealed multiple hypoechoic nodular lesions of varying sizes in the right submandibular region, abutting and displacing the right submandibular salivary gland. The largest of the lesions measured $3.4 \times 2.9 \mathrm{~cm}$ and matting was apparent (Figure 5). There were a number of other similar smaller lesions along the right jugular vein, which is suggestive of lymphadenopathy. The ultrasound report was consistent with that of right submandibular and jugular tuberculous lymphadenopathy.

Ultrasound-guided fine-needle aspiration biopsy (FNAB) revealed a cellular aspirate showing plenty of small and large lymphocytes. Necrotic debris was seen in focal areas, and few epithelioid cells or giant cells seen (Figures 6 and 7).

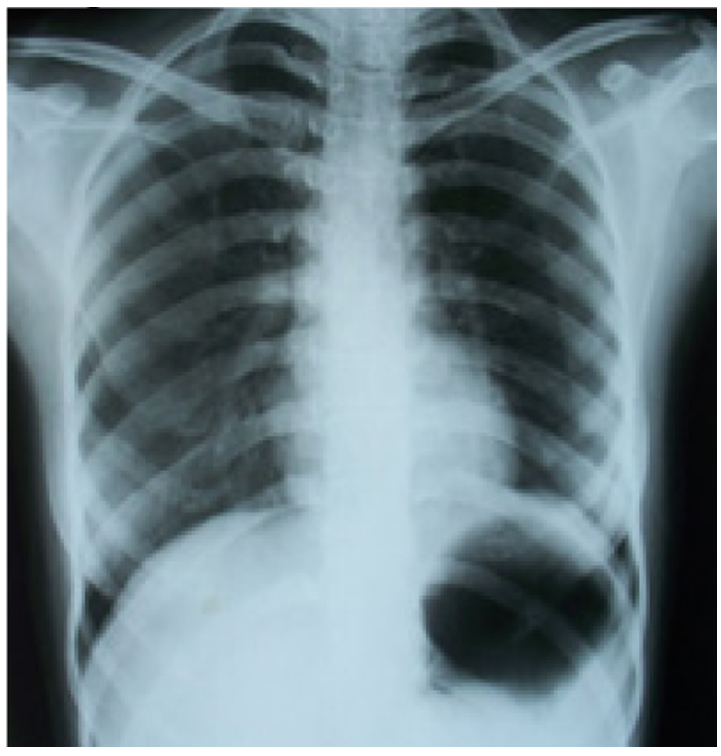

Figure 4 Chest radiograph showing no abnormality.

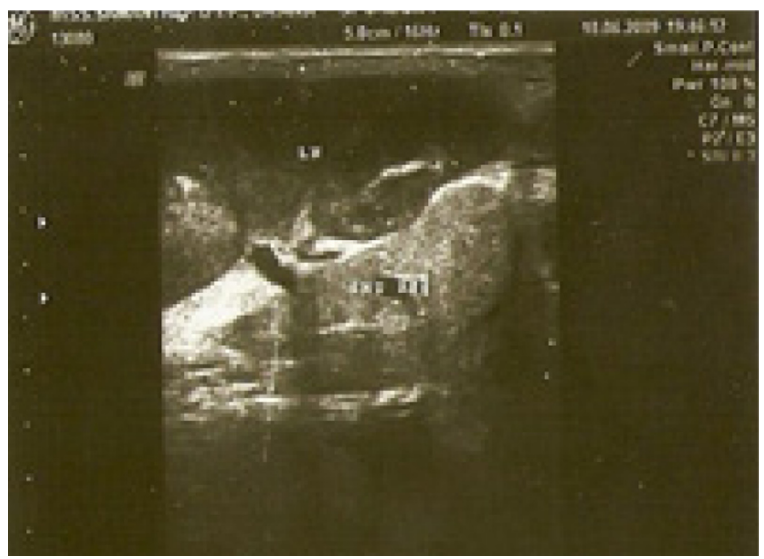

Figure $\mathbf{5}$ Ultrasound scan showing right submandibular tuberculosis lymphadenopathy.

The ultrasound-guided FNAB report was compatible with that of tuberculous lymphadenitis.

Regarding the clinical presentation of the case and the investigation reports a final diagnosis of right submandibular tuberculous lymphadenitis was arrived at. The patient was referred to the TB hospital for further treatment. Treatment consisted of anti-TB drugs for a period of 6 months. No complications occurred, and no further surgery was required.

\section{Discussion}

In the present case the patient had a swelling of about $4 \times 3 \mathrm{~cm}$ in the right submandibular region. Intraoral examination revealed no obvious odontogenic involvement, which could be the cause of the swelling. A panoramic radiograph of the affected area was taken to check for any underlying source of odontogenic involvement with respect to the swelling; it did not reveal any odontogenic origin in relation to the swelling and thus it was determined that the swelling was nonodontogenic in origin.

The presence of matting in the mass of the swelling and nonodontogenic nature of the swelling was taken into consideration for a clinical diagnosis of right submandibular tuberculous lympadinitis.

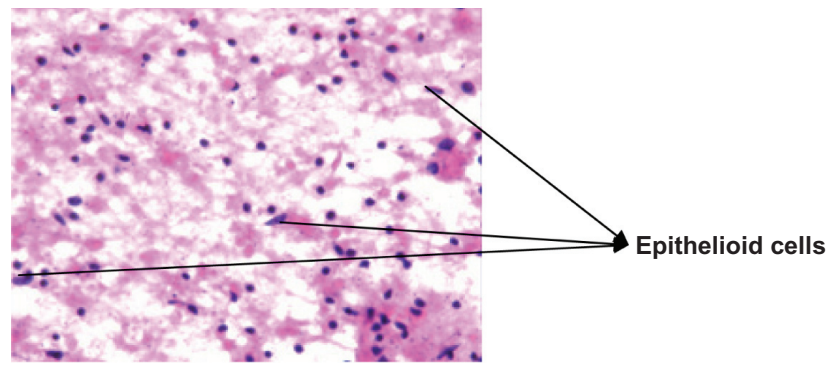

Figure 6 Fine needle aspiration biopsy showing epithelioid cells. 


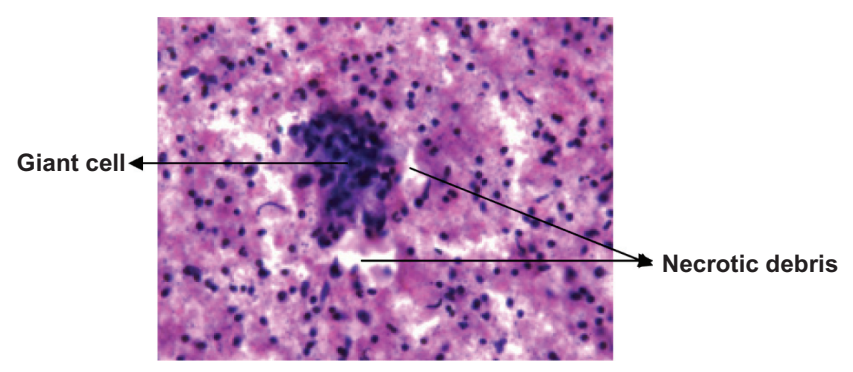

Figure 7 Fine needle aspiration biopsy showing giant cell and necrotic debris.

The target organ of MTB is the bronchopulmonary apparatus and the head and neck are usually secondary. ${ }^{16-22}$ The patient underwent a Mantoux test and complete hemogram. The Mantoux test was positive and the complete hemogram showed raised ESR $75 \mathrm{~mm}$ at 1 st hour, $105 \mathrm{~mm}$ at $2 \mathrm{nd}$ hour. The positive Mantoux test and the raised ESR further strengthened our clinical diagnosis of right submandibular tuberculous lymphadenitis. There is no single diagnostic test for $\mathrm{TB}^{23}$ although positivity for the tuberculin skin test was found in $84 \%$ of TB patients. ${ }^{24}$

A chest radiograph of the patient was taken and no abnormality was observed in the chest radiograph. If a tubercular lesion is suspected, a chest X-ray is indicated to investigate the possibility of pulmonary involvement. ${ }^{25}$ To evaluate the swelling further, an ultrasound scan of the patient was taken. The ultrasound scan report was consistent with that of right submandibular tuberculous lymphadenopathy.

With the results of all the above investigations pointing towards a diagnosis of TB lymphadenitis, an ultrasoundguided FNAB was carried out for the histopathological examination. The ultrasound-guided FNAB revealed clusters of epithelioid cells and few giant cells, which was compatible with that of tuberculous lymphadenitis. Fine needle aspiration is the most frequent and useful diagnostic technique available to diagnose lymph node TB. ${ }^{26}$

Histopathological examination of the biopsy specimens or material collected by fine needle aspiration of the cervical swellings was an important aid in the diagnosis of the disease because the finding of granulomatous lesions with epithelioid cells was highly suggestive of TB. The microbiological detection of mycobacteria was negative in almost $50 \%$ of the cultures and smears performed. ${ }^{24}$ The difficulties in detection of mycobacteria in orofacial TB, either by staining or by culture, are clearly reported in the literature. ${ }^{27}$

Primary TB of the orofacial region is more commonly found in children and adolescents than in adults. ${ }^{3,4}$ In the present case, adolescent age, poor socioeconomic and nutritional status of the patient, the clinical presentation of the case, and the investigation reports were taken into consideration for a final diagnosis of right submandibular primary tuberculous lymphadenitis.

\section{Summary}

TB affecting primarily cervical lymph nodes is uncommon. In absence of systemic signs and symptoms, as in our case, it can be difficult to diagnose TB. Awareness by the clinician of such a presentation would make diagnosis of TB easier. Diagnosis of the disease in the initial stages would be beneficial not only to the patient to allow them to receive early treatment, but also in preventing the spread of the disease to others. Thus, oral clinicians can contribute to the diagnosis of TB with awareness of the presentation of the disease and extra care in their regular practice.

\section{Disclosure}

The authors report no conflicts of interest in this work.

\section{References}

1. Crompton GK, Haslett C, Chilvers ER. Diseases of the respiratory system. Davidson's principles and practice of medicine. 18th ed. London, UK: Churchill Livingstone; 1999;347-353.

2. Lee KC, Schecter G. Tuberculous infection in the head and neck. Ear Nose Throat J. 1995;74:395-399.

3. Popowich L, Heydt S. Tuberculous cervical lymphadenitis. J Oral Maxillofac Surg. 1982;40:522-524.

4. Ishikawa H, Hyo Y. Tuberculous submandibular lymphadenitis. J Oral Maxillofac Surg. 1982;40:302-305.

5. Iype EM, Ramdas K, Pandey M, et al. Primary tuberculosis of the tongue: report of three cases. J Oral Maxillofaic Surg. 2001;39: $402-403$.

6. O'Conell JE, George MK, Speculand B, Pahor AL. Mycobacterial infection of the parotid gland: an unusual cause of parotid swelling. J Laryngol Ootal. 1993;107:561-564.

7. Hock-Liew E, Shin-Yu L, Chuang-Hwa Y, Wei-Jen C. Oral Tuberculosis. Oral Surg Oral Med Oral Pathol Oral Radiol Endod. 1996;81:415-420.

8. Phelan JA, Jimenez V, Tompkins DC. Tuberculosis: infectious diseases and dentistry. Dent Clin North Am. 1996;40:327-340.

9. Reichmand LB. The U shaped curve of concern. Am Rev Respir Dis. 1991;144:741-742.

10. Ito FA, de Andrade CR, Vargas PA, Jorge J, Lopes MA. Primary tuberculosis of the oral cavity. Oral Dis. 2005;11:50-53.

11. Rinaggio J. Tuberculosis. Dent Clin North Am. 2003;47:449-465.

12. Yepes JF, Sullivan J, Pento A. Tuberculosis: medical management update. Oral Surg Oral Med Oral Pathol Oral Radiol Endod. 2004;98:267-273

13. Aziz MA, Wright A, Laszlo A, DeMuynck A, Portaels F, VanDeun A. Epidemiology of antituberculosis drug resistance (The global project on antituberculosis drug resistance surveillance): an updated analysis. Lancet. 2006;368:2142-2154.

14. Prabhu SR, Sengupta SK. Bacterial infections due to mycobacteria. Oral Diseases in the Tropics. 1st ed. Oxford University Press; Delhi, India: 1993;195-202.

15. Ajay GN, Laxmikanth C, Prashanth SK. Tuberculous ulcer of tongue with oral complications of oral antituberculosis therapy. Ind J Dent Res. 2006;17:87-90.

16. Hashimoto Y, Tanioka H. Primary tuberculosis of the tongue: report of a case. J Oral Maxillofac Surg. 1989;47:744-746. 
17. Rauch MD, Friedman E. Systemic tuberculosis initially seen as an oral ulceration: report of case. J Oral Surg. 1978;36:387-389.

18. Prabhu SR, Daftary DK, Pholakia HM. Tuberculosis ulcer of the tongue: report of case. J Oral Surg. 1978;36:384-386.

19. Worsae N, Reibel J, Rechnitzer C. Tuberculous osteomyelitis of the mandible. Br J Oral Maxillofac Surg. 1984;22:93-98.

20. Haddad NM, Zaytoun GM, Hadi U.Tuberculosis of the soft palate and unusual presentation of OFT. Otolarynol Head Neck Surg. 1987;97:91-99.

21. Pande T.K, Hiran S, Rao VVB. Primary Lingual Tuberculosis caused by M. Bovis infection. Oral Surg Oral Med Oral Pathol Oral Radiol Endod. 1995;80:172-274.

22. Kolokotronis A, Antoniadis D, Trigonids G. Oral tuberculosis. Oral Dis. 1996;2:242-243.
23. Barga M, Blum JH, Graeme-Cook FM. A 57-year old man with fever and jaundice after intravesical installation of bacilli calmette-guerin for bladder cancer. Weekly clinicopathological exercises. $N$ Engl J Med. 1998;339:831-837.

24. Mignogna MD, Muzio LLO, Favia G, et al. Oral tuberculosis: a clinical evaluation of 42 cases. Oral Dis. 2000;6:25-30.

25. MacFarlane TW, Samaranayake LP. Clinical oral microbiology. Butterworth; London; 1989;112-115.

26. Chao SS, Loh KS, Tan KK, Chong SM. Tuberculous and non-tuberculous cervical lymphadenitis: A clinical review. Otolaryngol Head Neck Surg. 2002;126:176-179.

27. Hocking TL, Choi C. Tuberculosis: a strategy to detect and treat new and reactivated infections. Geriatrics. 1997;52:52-64.
Clinical, Cosmetic and Investigational Dentistry

\section{Publish your work in this journal}

Clinical, Cosmetic and Investigational Dentistry is an international, peer-reviewed, open access, online journal focusing on the latest clinical and experimental research in dentistry with specific emphasis on cosmetic interventions. Innovative developments in dental materials, techniques and devices that improve outcomes and patient satisfac-

\section{Dovepress}

tion and preference will be highlighted. The manuscript management system is completely online and includes a very quick and fair peerreview system, which is all easy to use. Visit http://www.dovepress. com/testimonials.php to read real quotes from published authors.

Submit your manuscript here: http://www.dovepress.com/clinical-cosmetic-and-investigational-dentistry-journal 